\title{
Sustainability of team building offers: survey of a growing market
}

\author{
A. Jiricka, E. Huesmann \& U. Pröbstl \\ Institute of Landscape Development, Recreation and Conservation \\ Planning, Department of Landscape, Spatial and Infrastructure Sciences, \\ University of Natural Resources and Applied Life Sciences, \\ Vienna, Austria
}

\begin{abstract}
Team building is a very heterogeneous field. An increase in demand and a corresponding expansion of offers can be observed for workplace-related and society-associated groups. This recent study examined 60 group-product offers for team building, and compared their product composition (target interest), their geographic location in Austria, their chosen environments and land-use intensity on location, as well as their communication of the offers to the outside. The aims and motivations for booking these new offers are quite diverse, but the most important factors proved to be enhancement of the internal atmosphere through improved communication, and a strengthening of team spirit. In many cases the rural setting is no more than a backdrop that can also be used as a form of sports arena with natural challenges. But sometimes the setting is also an active part of the offer, and contributes to reducing stress through its calming and inspiring nature. The study showed that most of the offers are set in near-natural environments, and only very few in urban areas. Most team building offers define themselves through sportive activities that play a clear consumer role on the landscape, or else they consist of events that are given a special feature precisely through being held in a natural environment. A closer look at the outdoor offers reveals that very sensitive near-natural areas are particularly frequented. Thereby, however, they also circumnavigate the traditional directive measures used in other recreation and tourism offers. There is, therefore, a risk that this increase in team building offers could have negative implications for the environment. On the other hand, this way of experiencing natural environments also has the power to kindle special emotional connections with a landscape - an
\end{abstract}


effect that is further intensified through the group experience. The study suggests that this aspect should be more closely researched in the future.

Keywords: team building, outdoor, natural resources.

\section{Introduction}

The field of touristic offers for team building is an expanding sector of tourism. At the same time, provider structure and the impact of company oriented tourism on the used natural resources has hardly been studied. In tertiary sector businesses, work processes are frequently structured into projects that are completed in teams. These teams can be spread out over various locations, each working on their own project. Businesses are having to deal with new tasks and must assign these tasks to employees, who have been trained through new educational backgrounds to be highly specialized in a certain area, without much of a sense for the greater context. But precisely this awareness of the greater context and identification with the business itself are very important factors for employees, and are therefore also important parts of adult education [1]. They counteract demotivation, work absence, sick leaves, a mentality of 'work to rule', and a fluctuation of qualified personnel, and are therefore economically relevant to the entire business.

One aspect, which has not received much attention as yet, is the significance of the natural landscape resources for this tourism sector. Just as the attractiveness of a destination is already an important factor, a landscape itself can also consciously be used as an essential element for team building. Past studies have dealt with the methods which are specific to outdoor trainings [2], their effectiveness [3] and the transferability of learning in these settings [4].

In our study we investigate the role of natural landscape resources in the composition and promotion of team building offers on the Austrian market. Regarding the sustainable development of tourism an additional question arises: whether natural landscapes are being merely 'consumed' by team building activities for the short term and without proper appreciation or reflection. To answer this question, our study compares which landscapes appear to be preferred by the providers, and how intensively they are used on a spatial and temporal scale. At the same time, the types of activity on offer and the promotion of the offers reveal the extent to which tourists are guided towards a respectful interaction with natural landscape resources.

A further research aspect - with a view to the social and economic sustainability of business tourism offers - is their integration into existing regional tourism offers, as well as their presentation of regional strengths and special features.

\section{Background}

In the field of business tourism, offers are primarily geared towards an overall goal, but there are many methods with which to reach this goal, and these in turn are reflected in each offer's setting. The following provides an overview of the 
possible structure of offers, and deals especially with their reference to nature and the environment as resources.

- Demand for professional training programs

Assisting employees to develop personally and professionally is not only an integral part of work laws; it also has direct benefits (e.g. development and expansion of team competence) and indirect benefits (e.g. greater satisfaction and identification with the business) for the employer.

Thus, it is in the interest of a business to promote its employees, and to assist them in this process on both a professional and personal level. There are three general aims in the field of human resource development [5], which are - in part - also reflected in touristic offers:

1. Concrete human resource development in the form of technical and personal advanced training and qualification.

2. Team development for more efficient team cooperation. This is achieved, for example, through events that train the behavioural level and analyse team and conflict behaviour.

3. Organisational development regarding structures and processes.

Human resource development is targeted at all employees, but the measures differ depending on levels of hierarchy, knowledge orientation and field-specific demand [1].

Different measures are applied in human resource development, depending on the target group: individuals, groups or workgroups and teams.

- Trends in team building characteristics

Concrete offers for businesses differ in their objectives regarding content, but also in structure, which is in turn defined by the overriding goal of human resource development. In the context of this goal, the term 'team' is seen as a general strategy of cooperation, but also as a constellation within the business, and brings with it the according process of 'team building'. The aspect of team building is of particular relevance in the context of this study, because certain natural landscape settings are beneficial in achieving this goal.

Beside traditional approaches using seminars, workshops, role games etc. new trends are focusing on experiential learning approaches. Experiential learning is a very specific approach. It integrates the elements nature, experience and a group aspect, and combines these elements in an educational way [6, 7].

Direct, intuitive behaviour can ideally be trained in the authentic situations presented by an outdoor setting, and thereby has a longer lasting effect. Classical examples of this approach are high ropes courses, rock climbing or white water rafting, etc. This approach has the greatest impact on natural areas, because it makes direct use of them. With respect to a sustainable development of tourism, these offers should therefore receive special attention, along with incentive offers. 
- Nature as part of the setting - touristic offers in a context of nature tourism

The teaching-psychological theory of constructivism emphasises the significance of the learning situation itself. In order to create an optimal learning space, the situation must be suited to the material being learned, and must be perceived as being authentic [8]. The setting has a part to play here, in that it can give the learning material a context of application, which can furthermore be regarded from different perspectives. The embedding in a landscape plays an important role. People not only perceive certain landscapes as being particularly attractive [9], a landscape can also be applied consciously as an instrument or as the backdrop for the programme.

In the case of an incentive, the learning content does not play as great a role as the destination itself, with which the employees are to be rewarded. From the point of view of the destination, the inclusion of various regional partners brings an economic and ideational advantage, as well as promoting identification within the region for a certain offer (sustainable tourism). After discovering a region during a business stay, visitors may well be curious to come again. Thus, a team building could have a positive effect on the sustainability of a region's tourism as a whole.

- Nature as a tool for team building

Team building offers should comprise activities that address the different learning types, and that include both mental and physical elements. These could be tasks that require logical consideration, but also creativity, coordination, communication, physical skill, etc. Natural settings are ideally suited to addressing different learning types and personal competences, due to their multisensual aspects and their complex and multifaceted structure.

Landscape and nature are the most important factors in the tourism marketing of many destinations. In team building offers (such as convention tourism), the scenic attractiveness of a destination is probable to be an important factor.

Regarding the offers examined during the course of this study (excluding conventions), it is especially interesting to determine whether the landscape is used only passively as a backdrop for the programme, or if it is actively incorporated and meant to set a certain atmosphere. This is reflected accordingly in the marketing of the offers (images and text).

\section{Methodology}

This study's underlying question is directed at the existing market of team building offers. In order to answer this question, an online survey was conducted. The field of touristic offers for professional team building is very heterogeneous. An increase in demand and a corresponding expansion of offers can be observed for workplace-related and society-associated groups. This study examined groupproduct offers for business clients, and compared their product composition (target interest), their geographic location in Austria, their chosen environments 
and land-use intensity on location, as well as their communication of the offers to the outside.

\subsection{Sample}

The 26 providers identified by the chosen method promoted a total of 551 offers over their websites. These were divided into different categories by the providers themselves (e.g. 'outdoor, fun and action', 'incentives and events', etc.). An exemplary offer was selected out of each of these pools to represent its category. This approach led to a total of 55 offers that were subsequently analysed in detail.

\subsection{Web mining}

This study makes use of web mining as a method of generating an overview of the existing team building and incentive offers in Austria. By this term, we understand the application of data-mining techniques with the intention of discovering and extracting information from web documents and services (Kosala and Blockeel [10]).

The procedure consists of four steps:

1. Finding web resources as objects of analysis

2. Selecting and pre-processing the web resources

3. Identifying general patterns

4. Analysing and interpreting these patterns

Web mining is divided into three sub-categories, depending on the focus of analysis. These are 'web structure mining' (analysis of link structures), 'web usage mining' (analysis of user clicks), and 'web content mining'.

The latter category, also known as 'online content mining (OCM)', is important for this study [11]. It deals with the information content of websites in this case, the promoted offers. The relevant content for this study includes the describing texts, images and hyperlinks. Videos, music and further metadata were disregarded.

In the following you can find a short overview of the criteria for the web mining process:

- Characteristics of the supplier

First of all the type of business was identified according to the four categories: Business Consultancy, Outdoor Sports Provider, Tourism Provider, Event Agency (see fig.1). Provider size was determined, based on the number of employees and the list of stated references. The latter, however, was probably not always complete. Therefore, in many cases, this factor is only of exemplary value. The provider agencies' experience and significance was evaluated, based on their list of references. This was done quantitatively on the one hand, by counting the stated references and noting the number in blocks. On the other hand, a qualitative inspection of the references distinguished different types of references according to size (medium enterprises, large enterprises and 


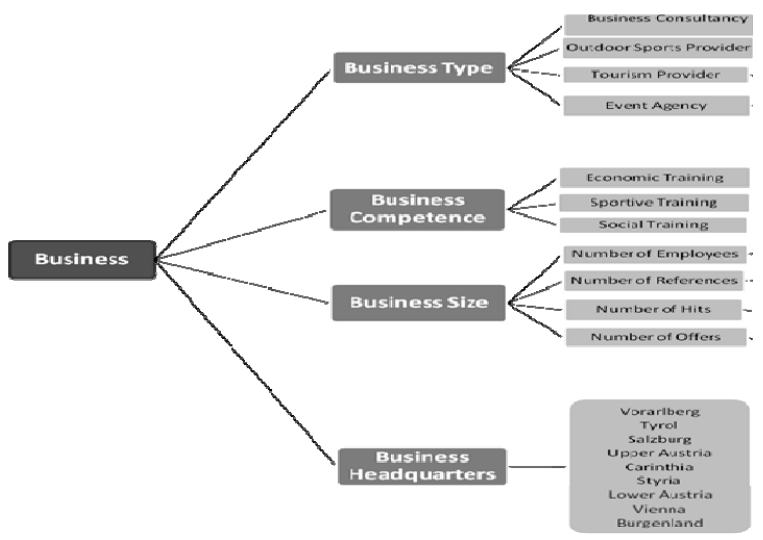

Figure 1: Web mining - criteria part 1 business structure.

corporations), and clustered them into blocks. Furthermore the business competences were viewed as well as their location in Austria.

- The importance of nature as a setting

Many team building offers make use of overlapping elements of a landscape. In experiential learning, on the other hand, the outdoor component is largely elementary. Therefore it is of interest to know which types of landscape areprimarily used. For this purpose, landscape type was classified into mountain, water, forest, open countryside, or combinations of these types - in accordance with the Austrian cultural landscape categories [12, 13].

- Nature as a tool for team building

A further component of each offer is its marketing - the way it is described to potential customers. In the case of web communication, this includes both the text and the images, which enrich the programme with emotions and associations. Again the role of the landscape as a tool for teambuilding was the central focus.

In order to make the written description of offers classifiable, a word frequency analyser was used to determine the number of words used, as well as their relative frequencies. Thus, dominant groups of words that evoke certain emotions could be identified (e.g. pertaining to the landscape: mountain, mountainside, slope, mountain panorama, raging river, beautiful view, nature, etc).

Only the text directly accompanying each offer was used for this analysis, not the text generally describing this category of offers, which sometimes includes descriptions of the methods.

Analysing these texts, the programme 'Word Frequency Analyser' was able to determine absolute word frequencies, but could not group words systematically. Thus, the dominant words did emerge, but interpretation of the results was hampered by the fact that the programme was not able to recognise 
semantic relations. Clustering the words retrospectively would be strongly subjective.

The images were analysed by counting the number of images per offer and assigning categories (1 image, 2-3 images, more than 3 images per offer). The motifs were also considered, and were used to classify the landscape into:

a) peaceful landscape: this includes gentle, green fields, low mountains, sunrises and sunsets, calm water, etc.

b) dramatic landscape: this includes raging rivers, cliff faces, whirling snow, etc.

c) neutral landscape: the portrayed landscape is not the central focus, but merely provides a backdrop for a scene (e.g. a simple green background).

- Possible impact on nature

We also examined whether landscape use was of a dynamic or constant nature. The term dynamic, in this sense, is used when spatial use is greater than $1 \mathrm{~km}^{2}$.

\section{Analysis of the market}

As can be seen in table 1, more than half of the offers are situated in the field of outdoor training, almost $35 \%$ are incentives, and fewer than $9 \%$ are seminars. Physical activity and sport as a method were used by $18 \%$ of all offers analysed. Examining the structure of these offers in closer detail showed that $40 \%$ of outdoor training offers purely use physical activity as a method. A larger part, almost half the entire number, uses a mix of two methods: physical activity and theoretical reflection thereafter. This approach corresponds to the theory of experiential learning, which states that social competences can be brought to the surface and highlighted through unaccustomed tasks. Another $18 \%$ of all offers analysed used purely theoretical, reflective methods - seminars, without exception.

Table 1: $\quad$ Structure of total offers.

\begin{tabular}{|c|c|c|}
\hline \multicolumn{3}{|c|}{ Structure of total offers, $n=551$} \\
\hline Outdoor training & Seminar & Incentive \\
\hline $57,0 \%$ & $8,7 \%$ & $34,3 \%$ \\
\hline
\end{tabular}

\subsection{The importance of nature as a setting}

The offers' spatial requirements and impact were examined, based on the offer descriptions. Altogether only two thirds of the offers could be assigned to any definite category.

Regarding outdoor spatial use, there is frequently an overlap between different types of landscape. Mountainous and aquatic landscapes in combination with open countryside are, however, most frequently stated (see table 2). Forest in combination with open countryside is the most appropriate setting for 
teambuilding which is not "action-driven" but based on remoteness or methodological challenges.

According to the results, almost $30 \%$ of the offer descriptions explicitly point out that there is no indoor aspect to their programmes. For those offers that do indicate an indoor aspect, almost a quarter refer to a regional connection. This leads one to conclude that programmes become attractive to customers not only through charismatic landscapes with mountains and water elements, but also through a region's special cultural features.

Table 2: $\quad$ Preferred types of (cultural) landscape.

\begin{tabular}{|c|c|c|c|c|c|c|}
\hline \multicolumn{7}{|c|}{ Spatial Use, $n=55$} \\
\hline \multicolumn{7}{|c|}{ Utilized Outdoor Space } \\
\hline $\begin{array}{c}\text { Forest and Open } \\
\text { Countryside }\end{array}$ & $\begin{array}{l}\text { Water and } \\
\text { Forest }\end{array}$ & $\begin{array}{l}\text { Water and } O . \\
\text { Country-side }\end{array}$ & $\begin{array}{c}\text { Mountain and } \\
\text { Open } \\
\text { Countryside }\end{array}$ & Mountain & City & $\mathrm{N} / \mathrm{A}$ \\
\hline $16 \%$ & $7 \%$ & $4 \%$ & $13 \%$ & $11 \%$ & $7 \%$ & $42 \%$ \\
\hline
\end{tabular}

\subsection{Nature as a tool for team building}

The visual component accompanying the written offer descriptions usually consisted of more than three images, which portrayed various motifs and atmospheres in order to convey an impression of the programme.

In those cases that showed landscape motifs (approx. $67 \%$ of the offers), these were mostly neutral landscapes acting as a backdrop rather than representing the central part of the programme.

\subsection{Possible impact on nature}

Almost half of the blocks made use of overlapping spatial structures (table 3). It became directly or indirectly clear from their descriptions that their programmes took place on an area of more than $1 \mathrm{~km}^{2}$. This indicates that space is consumed quite rapidly. Participants see a lot of the region, but probably hardly have enough time to get to know it more closely. Further studies would need to evaluate the pressure such rapid consumption exerts on a landscape from an environmental point of view.

From an economic sustainability point of view, the seasonal distribution of the offers indicates that team building offers can promote a more balanced use of tourism infrastructure (see table 3 ).

The impact on natural resources is also strongly influenced by the providers' competence in conveying the touristic programmes. In this respect, proper training and sensitisation of employees is important for sustainable interaction with the affected areas.

Providers' fields of competence were gathered from their own stated information on the educational background of their employees. This offers an 
Table 3: $\quad$ Spatial extent and seasonal distribution

\begin{tabular}{|c|c|c|c|c|c|}
\hline \multicolumn{6}{|c|}{ Spatial Extent, $n=55$} \\
\hline \multicolumn{2}{|c|}{ Dynamic } & \multicolumn{2}{|c|}{ Constant } & \multicolumn{2}{|c|}{ Not Identifiable } \\
\hline \multicolumn{2}{|c|}{$45 \%$} & \multicolumn{2}{|c|}{$35 \%$} & \multicolumn{2}{|c|}{$20 \%$} \\
\hline \multicolumn{6}{|c|}{ Seasonal Distribution of Offers, $n=55$} \\
\hline Winter & Spring & Summer & $\begin{array}{c}\text { multi- } \\
\text { seasonal }\end{array}$ & $\begin{array}{l}\text { Year } \\
\text { Round }\end{array}$ & $\mathrm{N} / \mathrm{A}$ \\
\hline $5 \%$ & $2 \%$ & $13 \%$ & $4 \%$ & $24 \%$ & $52 \%$ \\
\hline
\end{tabular}

indication of the providers' capability to conduct their programmes, and also hints at the quality of the programmes. The staff has a certain pool of acquired methods at their disposal, which they can employ during the course of a programme and during reflection thereafter.

Staff qualifications, however, were difficult to assess during web mining, because most of the providers did not provide this information on their websites. It was noticeable, though, that those with qualifications of a sportive nature did highlight these (see table 4). This is further indication of the heterogeneity of this sector, in which many people with a diversity of different trainings are active. Regarding the outdoor blocks, which frequently include high-risk sports, certifications and risk-minimisation, are important factors for customers, which may explain why these qualifications, in particular, are highlighted.

Table 4: $\quad$ Staff qualifications.

\begin{tabular}{|c|c|c|c|c|c|c|}
\hline \multicolumn{7}{|c|}{ Staff Training, $\mathrm{n}=26$} \\
\hline Sportive & $\begin{array}{c}\text { Sportive/ } \\
\text { Social }\end{array}$ & $\begin{array}{c}\text { Sportive/ } \\
\text { Economic }\end{array}$ & $\begin{array}{c}\text { Sport./ } \\
\text { Econ./ } \\
\text { Experiential } \\
\text { Learning }\end{array}$ & $\begin{array}{c}\text { Soc./ } \\
\text { Experiential } \\
\text { Learning }\end{array}$ & Economic & N/A \\
\hline $12 \%$ & $4 \%$ & $4 \%$ & $8 \%$ & $4 \%$ & $4 \%$ & $64 \%$ \\
\hline
\end{tabular}

This first analysis illustrated that there is little previous knowledge regarding sustainable development of tourism or environmental education in the field of team building offers. Further examination of this aspect through different methods (e.g. interviews with providers) is suggested, because the sample size during this study was not sufficient to answer this question. Employee training regarding a cautious and sustainable interaction with nature and natural resources should be queried and studied more closely with a focus on quality management.

\section{Discussion}

The study revealed that the choice of location plays a role for the setting and the learning situation. More than half of the analysed offers are situated in the outdoor sector. Use of outdoor space usually overlaps more than one landscape 
type. Nevertheless, the hypothesis that team building offers frequently make use of charismatic landscapes, and consume these on a large scale, seems to be confirmed. Mountainous and aquatic landscapes in combination with open countryside are most frequently stated. All of the analysed offers made use of at least $1 \mathrm{~km}^{2}$ of either water or mountain landscape. Due to movement through the landscape, the impact is not concentrated on a small area. Settings are alternated in order to allow participants many new experiences, but the practical suitability of the selected landscape for the intended methods is given greater priority than considerations for the sensitivity of the landscape (provided the trainers are even able to recognise this factor).

A closer look at the outdoor offers reveals that very sensitive near-natural areas are particularly frequented. The offers are rarely related to traditional recreation areas, instead aiming to deliver less known and frequented 'gems' of nature. Thereby, however, they also circumnavigate the traditional directive measures used in other recreation and tourism offers.

The tendency towards a continuous introduction of new trend sports, thereby utilising natural landscape resources in ever new ways, is exerting increasing pressure on valuable landscapes [7]. The essence of (outdoor) sports programmes - overcoming natural barriers and obstacles through the power of one's own body and with the help of sports equipment - is the priority in this process. The principles of experiential learning promote this effect, because remoteness can be part of the concept [15]. Depending on the aim or tasks set by the team building programme, confrontation with personal or team limits and options is more strongly influenced either by the method itself or by the setting (remoteness, tranquillity).

In principle, when making use of a landscape, there is always the option of also conveying an appreciation for the landscape through its use. Attractive, aesthetically beautiful landscapes, above all, attract people and remain in their memories. However, the trainer's influence, previous knowledge and sensibility towards a sustainable interaction with the natural resources play an important role in this respect. This study shows that trainers' professional education is mostly geared towards economic and human resource development competences. This means that a majority of trainers is not even able to recognize their programme's impact on natural resources, and therefore will not be able to pass on any information on the landscapes sensitivity to the participants. In developing and expanding these offers, sensitisation of trainers would therefore be an important task with a view to a gentle, responsible interaction with the impacted natural resources (e.g. protection of trees, garbage disposal, etc.) [16].

Furthermore, the analysis showed that most of the offers originate in urban areas and are conducted in the regional landscapes by outside trainers. In terms of social and economic sustainability, this precludes the possibility of utilising regional resources and demonstrating these to the participants. 


\section{Conclusion and outlook}

Web mining very successfully revealed the diverse structure of this sector. Indeed, many different business forms are active in the field, together providing a large pool of conventional and novel products.

The providers themselves are mostly small and medium enterprises, employing staff with very diverse educational backgrounds. Former training in the field of environmental education, sustainable resource use or sustainable tourism management is usually not to be found.

A considerable part of the offers chooses regional elements of landscape and nature as the setting for their products. Most team building offers define themselves through sportive activities that play a clear consumer role on the landscape, or else they consist of events that are given a special feature precisely through being held in a natural environment. But even conventional seminars or advanced training courses are often intentionally held externally in areas of particular scenic beauty.

There is, therefore, a risk that this increase in business touristic offers could have negative implications for the environment. On the other hand, this way of experiencing natural environments also has the power to kindle special emotional connections with a landscape - an effect that is further intensified through the group experience. In these situations, it should be possible to convey additional information for a better understanding of the landscape, and to anchor this acquired knowledge in the long term through the emotional connection. The study suggests that this aspect should be more closely researched in the future.

\section{References}

[1] Michalk, S. and Nieder, P., Modernes Personalmanagement: Grundlagen, Konzepte, Instrumente, 1. Aufl., Wiley-VCH Verlag GmbH \& Co. KGaA, 2009.

[2] Shivers-Blackwell, Reactions to outdoor teambuilding initiatives in MBA education, Journal of Management Development, Volume 23, Issue 7, pp.614-630, 2004.

[3] Tannenbaum, S., Beard, R. L., Salas, E., Chapter 5 Team Building and its Influence on Team Effectiveness: an Examination of Conceptual and Empirical Development. In: Advances in Psychology, Volume 82, pp. 117153, 1992.

[4] Williams, S., Graham, S., Baker, B. Evaluating outdoor experiential training for leadership and team building. In: Journal of Management Development, Vol. 22 Iss: 1, pp. 45-59, 2003.

[5] Becker, M.,. Personalentwicklung 4., aktualis. u. überarb. A., 2005.

[6] Heckmair, B. and Michl, W., Einführung in die Erlebnispädagogik; Ernst Reinhardt Verlag; München, 2004.

[7] Scheurer; R., Erlebnis-Setting - Touristische Angebotsgestaltung in der Erlebnisökonomie; Berner Studien zu Freizeit und Tourismus Nr. 43; Bern, 2003. 
[8] Quilling, E. and Nicolini, H.J., Erfolgreiche Seminargestaltung: Strategien und Methoden in der Erwachsenenbildung 2., erw. Aufl. 2009., VS Verlag für Sozialwissenschaften, 2009.

[9] Appleton, J., The experience of landscape, Chichester; New York: 1975.

[10] Kosala, R. and Blockeel, H. Web Mining Research: A Survey. In: SIGKDD Explorations, Vol. 2 Iss. 12000 p. $2 \mathrm{f}$

[11] Wrbka, T., Fink, M., Beissmann, H. et al. Kulturlandschaftsgliederung Österreich, Endbericht des gleichnamigen Forschungsprojektes, 2002.

[12] Breitner, M. and Sohns, K., Online Content Mining als Instrument im Hochschulmanagement. In: M. Breitner and K. Sohns, hrsg. Perspektiven des Lebenslangen Lernens - dynamische Bildungsnetzwerke, Geschäftsmodelle, Trends. GITO mbH Verlag, 2010.

[13] Freyer, W., Tourismus. Einführung in die Fremdenverkehrsökonomie 8., überarb. und aktualis. A., Oldenbourg, 2006.

[14] Rüdisser, J. and Tasser E., Landbedeckung Österreichs: Datenintegration und Modellierun. In: Strobl et. al. Angewandte Geoinformatik 2011 Beiträge zum 21. AGIT Symposium Salzburg,2011.

[15] Hindinger, F., Pröbstl U., Führt der Boom im Hallenklettern zu mehr Naturbelastung? Ergebnisse einer Befragung in Wiener Kletterhallten.. Naturschutz und Landschaftsplanung, 43(4), 117-122, 2011.

[16] Muff, A., Erlebnispädagogik und ökologische Verantwortung: Erleben und Handeln im Spannungsfeld von Naturnutzung und Naturschutz.; AFRAVerl. 2001. 